\title{
Strategies to Optimize the Efficacy of Anthelmintic Drugs in Ruminants
}

\author{
Carlos Lanusse, ${ }^{1, \star}$ Candela Canton, ${ }^{1}$ Guillermo Virkel, ${ }^{1}$ Luis Alvarez, ${ }^{1}$ Livio Costa-Junior, ${ }^{2}$ and \\ Adrian Lifschitz ${ }^{1}$
}

Anthelmintic resistance in human and animal pathogenic helminths has been spreading in prevalence and severity. Multidrug resistance is a widespread problem in livestock animals. The use of available pharmacology-based information is critical to the design of successful future approaches for parasite control. Relevant scientific work supporting the main strategies to optimize anthelmintic therapy in ruminants under the current drug-resistance scenario is described here. We emphasize the need for further integrated pharmacoparasitological knowledge to extend the lifespan of both traditional and novel anthelmintic compounds, and to progress in the identification of complementary/alternative measures of parasite control in livestock animals.

\section{Resistance-Related Failures in Anthelmintic Therapy}

Nematode parasites of ruminants account for one of the largest infectious disease problems in grazing livestock systems worldwide. Despite promising research results, nonchemical control approaches are not yet available for routine commercial use, and parasite control in livestock still relies on the use of synthetic antiparasitic drugs, which comprise the largest sector of the animal pharmaceutical industry [1]. The integration of available information on the host-parasite-environment relationship, with the understanding of the pharmacological properties of existing drugs, has contributed to more efficient parasite control. The excellent broad-spectrum efficacy, good tolerability, and low costs of the available synthetic anthelmintic drugs (see Glossary) have accounted for their extended use in livestock animals during the last 50-60 years. However, the over-reliance on anthelmintics and their inadequate use has led to therapeutic failures and to the widespread development of parasite resistance.

Most fields of chemotherapy benefit from in vitro test systems that can be used to accurately predict drug concentrations required for efficacy in vivo. It has been difficult to develop a culture system for nematodes to determine in vitro potency for anthelmintics [2]. This inconvenience, a key limitation in estimating the active drug concentration required to achieve optimal in vivo activity, has hindered further development in the field. However, the progress made on our comprehension of the pharmacokinetic and pharmacodynamic mechanisms of drug action has been sufficient to achieve a deep understanding of the pharmacology of the main chemical families. The time of parasite exposure to adequate levels of active drug determines the efficacy and/or persistence of activity for most of the anthelmintics used in ruminants (Box 1). The therapeutic failures due to the widespread development of multiresistant nematode parasites affecting livestock animals pose a huge scientific challenge. Here we review the main available valid pharmacological strategies to optimize control under a complex multidrugresistance situation (Figure 1, Key Figure).
Highlights

Considering the increasing concern regarding the development of drug resistance, the use of pharmacologybased information is critical to design successful strategies for future helminth parasite control in livestock.

Integrated pharmacokinetic/pharmacodynamic and clinical pharmacology knowledge is required to preserve both well-established and modern anthelmintics.

Assessment of drug disposition in the host and comprehension of the mechanisms of drug influx/efflux/detoxification in different target helminths, have signified relevant progress in anthelmintic therapy in ruminants.

Different pharmacokinetic-based approaches to enhance parasite exposure (pharmacokinetic optimisation) and the use of a mixture of molecules from different chemical families (drug combinations) have been assessed as valid strategies to control resistant parasites and to slow the selection for further resistance.

Identification/development of complementary and/or alternative (i.e., bioactive phytochemicals) measures seems critical to achieve sustained parasite control in livestock.

${ }^{1}$ Laboratorio de Farmacología, Centro de Investigación Veterinaria de Tandil (CIVETAN), UNCPBA-CONICET-

CICPBA, Facultad de Ciencias Veterinarias, Campus Universitario, (7000) Tandil, Argentina

${ }^{2}$ Centro de Ciências Biológicas e da Saúde, Universidade Federal do Maranhão, Brazil

${ }^{*}$ Correspondence: clanusse@vet.unicen.edu.ar (C. Lanusse). 


\section{Box 1. Pharmacokinetic Principles Supporting Drug Anthelmintic Activity}

The overall pharmacokinetic process, including drug absorption, tissue distribution, and its biotransformation/elimination pattern, is crucial for allowing the drug to reach the target parasites located in different tissues at sufficient concentrations/time to exert its anthelmintic effect (Figure I). There is a strong relationship between pharmacokinetics (which determine drug exposure at the parasite location site) and pharmacodynamics (drug effect). Dissolution of drug particles in gastrointestinal (Gl) fluids is a particularly important phenomenon for drugs administered as suspensions by the oral route (such as benzimidazole compounds, morantel/pyrantel, etc.). Dissolution is a crucial step because drug particles must dissolve in the enteric fluids in order to allow absorption through the Gl mucosa and/or penetration through the external surface of helminth parasites located in the digestive tract [99]. The undissolved drug particles passing down the Gl tract in the luminal content are excreted in feces without exerting its action. Anthelmintic compounds formulated as drug solutions for parenteral injection in domestic animals (macrocyclic lactones, levamisole, etc.) do not require dissolution before systemic absorption. In those cases, the digestive secretion process (i.e., abomasal secretion) is an important step to assure drug-nematode contact. Drug absorption is a main limiting factor that determines the amount of drug reaching the systemic circulation (systemic exposure). The reversible exchange between the bloodstream and tissues allows the drug and/or metabolites to achieve concentrations that are anthelmintically active at the tissues of parasite location [99].

Drug entry and accumulation into target helminths are critical issues to achieve optimal efficacy. Both in vivo and ex vivo studies have shown that transcuticular/tegumental diffusion is a relevant pathway for drug entrance into helminths (including blood-sucking parasites), which is dependent on lipophilicity as a major physicochemical determinant of drug capability to reach therapeutic concentrations within the parasite [100]. It is evident that drug entry into a helminth parasite is crucial to achieve sufficient drug concentration at the site of action to exert the anthelmintic action. However, the accumulation of active drug at the site of action will depend on the balance among drug entry (influx), the parasités capacity to inactivate the drug metabolically, and drug efflux mediated by transporter proteins [101]. The time of parasite exposure to active drug concentrations determines the efficacy and/or persistence of activity for most of the anthelmintics used in ruminants. Altogether, these different factors will determine the final anthelmintic activity, as is shown schematically in Figure I.

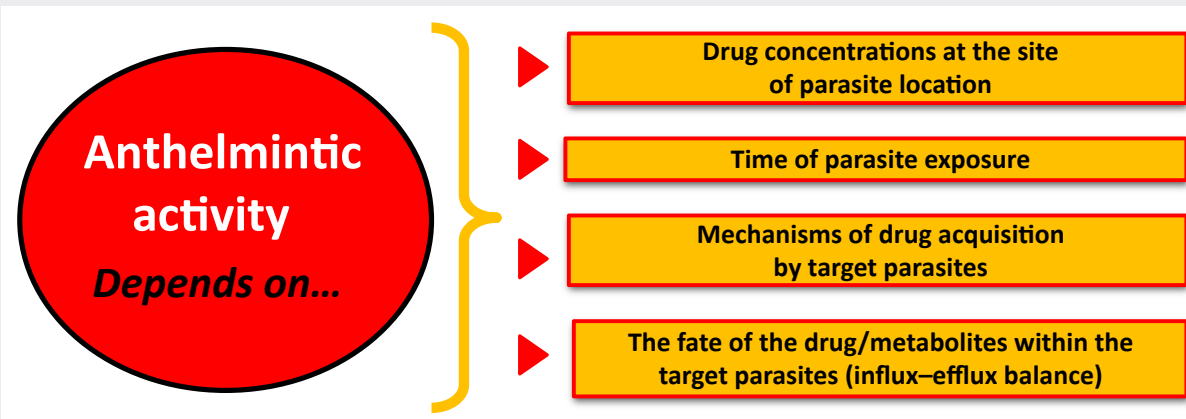

Trends in Parasitology

Figure I. Key Pharmacological Issues on Which Anthelmintic Activity Depends.

\section{Pharmacokinetic-Based Optimization of Drug Activity \\ Absorption-Related Enhancement of Drug Systemic Availability and Target Parasite \\ Exposure}

Pharmacokinetic processes directly influence the drug concentration level attained at the site of action and the resultant pharmacological effect (Box 1). The main pathogenic parasites affecting domestic animals and humans live in predilection sites, where food/energy from the host can be easily obtained, such as the gastrointestinal (Gl) lumen and mucosa, liver, bile duct, lung, and skin. Anthelmintic drugs require effective concentrations attained at those sites of parasite location for a certain period. The physicochemical properties and pharmacokinetic disposition of these drugs have a direct influence on their anthelmintic activity [3] (Box 1). Due to the great difficulties associated with developing new anthelmintic molecules, optimization of the existing compounds has been a high priority for research in the field. A main strategy to optimize

\section{Glossary}

Anthelmintics: benzimidazoles, imidazothiazoles (levamisole), macrocyclic lactones, salicylanilides (closantel), tetrahydropyrimidines (morantel, pyrantel), organophosphates (coumaphos, naphthalophos, etc.) and the novel spiroindole (derquantel) and aminoacetonitrile derivatives (monepantel), are the main chemical families of synthetic anthelmintics used to control nematode infections in ruminants.

Benzimidazoles: the benzimidazole methylcarbamates albendazole, fenbendazole, and their sulphoxide derivatives are among the most extensively used anthelmintics. They are active against larval/adult stages of gastrointestinal (GI) and lungworm nematodes, eggs (ovicidal) and tapeworms. Triclabendazole is the main available flukicidal drug, active against immature and mature liver flukes.

Bioactive phytochemicals: these are a variety of plant-derived (natural) compounds with different therapeutic activities. The terpenes, condensed tannins, and flavonoids are among the natural products with well demonstrated anthelmintic activity. Drug combination treatment: this is defined as the use of two or more anthelmintic drugs with a similar spectrum of activity and different mode of action/resistance to treat a single disease (i.e., Gl parasitism).

\section{Drug-metabolizing enzymes:}

phase 1 (oxidative, reductive, hydrolytic) or phase 2 (conjugative) enzymes devoted to the biotransformation of endo- and xenobiotics, including therapeutically used drugs.

Drug systemic exposure: the total drug availability in the body expressed as the AUC (area under the drug/metabolite concentrationtime curve). AUC is proportional to the total amount of drug absorbed. Drug-transport proteins: ATPbinding cassette $(A B C)$ transporters are transmembrane proteins found in all living organisms. They are responsible for the ATP-dependent transport of a wide variety of drugs, lipids, and metabolic products across the plasma membrane and intracellular membranes. $\mathrm{P}$ glycoprotein (P-gp) is the most well 
the use of existing anthelmintic drugs has been focused on the pharmacokinetic-based enhancement of parasite exposure, which is now a well established pharmacological tool to optimize anthelmintic therapy and delay the development of anthelmintic resistance. A Monte-Carlo simulation of resistant-gene frequencies following treatment has indicated that low and/or variable (erratic) worm exposure to the active drug accounts for the increased frequency of resistance genes within a population [4]. Several pharmacological strategies allowing the enhancement of drug systemic exposure (availability) and parasite exposure have been deeply investigated and extensively reviewed in the literature. Alternative pharmaceutical approaches to improve drug formulations and management of animal feeding (fasting and feed restriction) have been extensively studied as alternatives to improve the poor/erratic Gl absorption and to enhance the systemic exposure of the widely used broad-spectrum benzimidazole anthelmintics (Box 2). The chosen route of drug administration may also play a relevant role in optimizing systemic exposure and efficacy of the highly lipophilic macrocyclic lactone endectocide compounds against resistant nematodes in different animal species (Box 2). Additionally, the evaluation of increased drug dosage levels has shown that accumulation within target parasites is directly related to the drug concentration available in the environment where the nematodes are located. Increasing drug exposure may be a useful strategy for killing heterozygous resistant parasites present during the earliest phases of resistance development [5] (Figure 1).

The complex interactions among drug physicochemical properties, pharmaceutical preparations, routes of administration and dose rate directly influence the resultant kinetic behavior and the therapeutic efficacy of the different antiparasitic drugs (Box 2). Integrated understanding of these pharmacological properties and the development of new formulations assuring increased parasite exposure to the active drug may help to avoid misuse and prolong the lifespan of the existing or novel anthelmintics.

\section{Modulation of Drug-Metabolizing Enzymes}

Anthelmintic drugs are biotransformed by different drug-metabolizing enzymes from both hepatic and extrahepatic tissues. Metabolic conversions usually alter the polarity of the anthelmintic parent molecule and, consequently, the way in which the drug is distributed and excreted from the body. In vivo interference with the activity of certain drug-metabolizing enzymes may give rise to pronounced modifications to both the pharmacokinetic behavior and the therapeutic outcome of active anthelmintic molecules. Modulation/inhibition of the metabolic activity may contribute to enhance the systemic exposure of active anthelmintic drugs (Box 3). This rationale was pursued in a number of investigations assessing the pharmacokinetics and efficacy of benzimidazole compounds. Their intrinsic anthelmintic action, based on the disruption of basic cell functions depending on the integrity of the microtubule system, requires their sustained presence at the site of parasite location [6]. Consequently, extension of the residence time of active benzimidazole molecules in the bloodstream is relevant for their efficacy. Since these compounds are extensively metabolized in the liver, the inhibition of certain metabolic pathways may have a relevant impact on their anthelmintic efficacy. In this regard, parent thioether benzimidazoles, such as albendazole, fenbendazole, and triclabendazole, undergo a two-step S-oxidation that renders sulphoxide and sulphone metabolites. Mixed-function oxidases belonging to flavin-monooxygenase (FMO) and cytochrome P450 (CYP) families were found to be involved in the hepatic S-oxidation of these drugs in ruminants $[7,8]$. In terms of parasite uptake/accumulation [9] and mode of action (binding to tubulin) [10], parent thioethers are more efficient than their respective S-oxidized metabolites. Compared to their parent drugs, sulphoxide metabolites have less anthelmintic potency, and sulphones are virtually inactive. Indeed, oxidative metabolism in the liver results in a considerable reduction of studied ABC transporter which is able to pump a broad range of structurally and functionally unrelated compounds out of the cell (efflux process). P-gp is widely distributed in mammalian tissues and is associated with a phenotype of multidrug resistance to anticancer, antimicrobials, and anthelmintic drugs.

Macrocyclic lactones: the avermectins (abamectin, ivermectin, doramectin) and milbemycins (moxidectin) are closely related 16membered macrocyclic lactones, active at extremely low $(0.2 \mathrm{mg} / \mathrm{kg})$ dosages against endo- and ectoparasites (endectocides). The long persistence of the broadspectrum anthelmintic activity against adult and immature nematodes is supported by their extensive tissue distribution and prolonged residence in the digestive mucosal tissue.

Parasite exposure: refers to the amount of drug accumulated within a target parasite as a result of the drug influx-detoxification-efflux balance.

Pharmacodynamics: the response of the body to the drug, including the characterization of the drug-receptor interaction. Pharmacodynamics deals with the mechanism(s) of drug action.

Pharmacodynamic interactions: interactions occurring when one drug may alter the intensity of the pharmacological effects of another drug when given concurrently. Drugto-drug interactions can lead to both enhanced (additive or synergic effects) and diminished (antagonism) drug responses. Additive: the combined activity of two drugs equals the sum of their independent activities measured separately. Synergism: the combined effects of two active ingredients are significantly greater than their independent effects. Antagonism: the combined effect is lower than the sum of effects induced by each individual drug.

Pharmacokinetics: pharmacokinetics involves the time course of drug absorption, distribution, metabolism, and elimination from the host, which, in turn, determines the concentration of the active drug reaching both the site (tissue) of parasite location and the target worm. 


\section{Box 2. Absorption-Mediated Enhancement of Target Parasite Exposure to the Active Drug}

Different drug-absorption-related approaches addressed to enhance parasite exposure have been proposed as valid strategies to improve anthelmintic efficacy.

\section{Improved Drug Formulations}

Poor/erratic gastrointestinal (Gl) absorption hinders the clinical efficacy of benzimidazole compounds. Different pharmacotechnical strategies have been assayed to overcome their lack of water solubility (Table I). Amphiphilic surfactants improved the absorption and systemic availability of albendazole metabolites in cattle [102]. Complexation with cyclodextrins markedly increased the plasma availability of flubendazole metabolites in mice and pigs $[103,104]$ compared to a conventional suspension. Similarly, cyclodextrin-based solutions [103,105,106], solid dispersions [107], and lipid nanocapsules [108] (Table I) have been used to enhance albendazole absorption, improving the systemic exposure of its active sulphoxide metabolite.

\section{Animal Feeding}

Considering that low abomasal $\mathrm{pH}$ facilitates the dissolution of benzimidazole particles, fasting and/or reducing feed intake prior to their oral administration drastically enhance drug absorption and systemic exposure of active metabolites in sheep and cattle [109-111] (Table I). The delayed rate of passage of the drug down the digestive tract observed in fasted animals accounted for increased dissolution (abomasum) and enhanced intestinal absorption, which correlated with a marked enhancement in drug concentrations recovered from the digestive tract and tissues [109]. Those feedmanagement-related therapeutic advantages are nowadays extensively used under field conditions.

\section{Route of Administration}

Oral administration accounted for markedly higher ivermectin concentrations recovered at the Gl contents in comparison to the parenteral treatment, which was reflected in enhanced drug accumulation within Haemonchus contortus collected from treated sheep and improved efficacy [112] (Table I). The advantage of the oral route has also been demonstrated for other macrocyclic lactones in cattle $[58,113]$. Only when worms with reduced susceptibility are predominant can an improved efficacy for the oral treatment be observed. Enhanced drug exposure of resistant worms located at the lumen of the abomasum/small intestine may account for that therapeutic advantage.

\section{Dosage Levels}

Increases in the effective dose rate for ivermectin and moxidectin (double dose) and albendazole (triple dose) in sheep have accounted for enhanced drug exposure at the tissues of parasite location, as well as for improved drug accumulation within a highly resistant $H$. contortus isolate collected from treated animals [114-116] (Table I). Although useful from an experimental point of view, the risk of an extensively wide recommendation for the use of high dosages in livestock practice may be associated with the selection of highly resistant nematodes, and to the adverse impact of the presence of drug residues in edible tissues.

Table I. Approaches Investigated to Enhance the Absorption and Systemic Availability of Anthelmintic Drugs in Different Animal Species

\begin{tabular}{|l|l|l|l|l|l|}
\hline Approach & $\begin{array}{l}\text { Anthelmintic } \\
\text { drug }\end{array}$ & $\begin{array}{l}\text { Animal } \\
\text { species }\end{array}$ & $\begin{array}{l}\text { Pharmacokinetic } \\
\text { modification }\end{array}$ & $\begin{array}{l}\text { Changes in therapeu- } \\
\text { tic response }\end{array}$ & Refs \\
\hline Modified drug formulation & ABZ & Cattle & $\begin{array}{l}\text { Up to 164\% increase } \\
\text { in AUC }\end{array}$ & NA & {$[102]$} \\
\hline $\begin{array}{l}\text { Amphiphilic } \\
\text { surfactants }\end{array}$ & FLBZ & Mice & $\begin{array}{l}27 \text {-fold AUC } \\
\text { increase }\end{array}$ & $\begin{array}{l}\text { Reduction of the } \\
\text { Equinococcus } \\
\text { granulosus cysts weight } \\
\text { 7-fold greater than the } \\
\text { Suspension treatment }\end{array}$ & {$[103]$} \\
\hline Solid dispersions & FLBZ & Pigs & $\begin{array}{l}\text { 6.6-fold AUC } \\
\text { increase }\end{array}$ & NA & {$[104]$} \\
\hline & Mice & $\begin{array}{l}1.5 \text {-fold AUC } \\
\text { increase }\end{array}$ & NA & {$[107]$} \\
\hline
\end{tabular}

Pharmacokinetic interactions: occur when a drug compound modifies the pharmacokinetic behavior of a second drug. As a consequence, active drug concentrations at the site of action may be either increased (positive interaction) or decreased (negative interaction).

Refugia: the parasite population 'escaping' or 'not exposed' to the anthelmintic treatment (i.e., free-living stages in the environment at the time of treatment). 
Table I. (continued)

\begin{tabular}{|c|c|c|c|c|c|}
\hline Approach & $\begin{array}{l}\text { Anthelmintic } \\
\text { drug }\end{array}$ & $\begin{array}{l}\text { Animal } \\
\text { species }\end{array}$ & $\begin{array}{l}\text { Pharmacokinetic } \\
\text { modification }\end{array}$ & $\begin{array}{l}\text { Changes in therapeu- } \\
\text { tic response }\end{array}$ & Refs \\
\hline Lipid nanocapsules & $A B Z$ & Mice & $\begin{array}{l}\text { 2.2-fold AUC } \\
\text { increase within } \\
\text { hydatid cysts } \\
\text { collected from } \\
\text { infected mice }\end{array}$ & $\begin{array}{l}\text { Efficacy increase (from } \\
47 \% \text { to } 91 \% \text { ) against } \\
\text { hydatid cysts }\end{array}$ & {$[108]$} \\
\hline \multicolumn{6}{|c|}{ Animal feeding management } \\
\hline Reduced feed intake & OFZ & Sheep & $\begin{array}{l}\text { 1.6-fold AUC } \\
\text { increase }\end{array}$ & $\begin{array}{l}\text { Efficacy increase (from } \\
60 \text { to } 94 \% \text { ) against } \\
\text { resistant Haemonchus } \\
\text { contortus }\end{array}$ & {$[110]$} \\
\hline \multirow[t]{2}{*}{$\begin{array}{l}\text { Full fasting prior to } \\
\text { treatment }\end{array}$} & $\mathrm{ABZ}$ & Cattle & $\begin{array}{l}\text { 2-fold AUC increase. } \\
\text { Marked } \\
\text { enhancement of } \\
\text { drug exposure at the } \\
\text { Gl tract }\end{array}$ & NA & {$[109]$} \\
\hline & $\mathrm{ABZ}$ & Sheep & $\begin{array}{l}\text { 1.6-fold AUC } \\
\text { increase. Marked } \\
\text { enhancement of } \\
\text { drug exposure at the } \\
\text { Gl tract }\end{array}$ & $\begin{array}{l}\text { Efficacy increase (from } \\
74 \text { to } 90 \% \text { ) against } \\
\text { resistant } H . \text { contortus }\end{array}$ & {$[111]$} \\
\hline \multicolumn{6}{|c|}{ Routes of administration } \\
\hline \multirow[t]{3}{*}{$\begin{array}{l}\text { Oral versus } \\
\text { subcutaneous } \\
\text { treatment } \\
\text { (therapeutic dose } \\
\text { rates) }\end{array}$} & IVM & Sheep & $\begin{array}{l}\text { 14-fold increase in } \\
\text { drug concentrations } \\
\text { within adult } H \text {. } \\
\text { contortus }\end{array}$ & $\begin{array}{l}\text { Efficacy increase (from } 0 \\
\text { to } 40 \% \text { ) against IVM- } \\
\text { resistant } H \text {. contortus }\end{array}$ & {$[112]$} \\
\hline & IVM & Horses & NA & $\begin{array}{l}\text { Efficacy increase (from } \\
36 \text { to } 100 \% \text { ) against adult } \\
\text { cyathostomins }\end{array}$ & {$[118]$} \\
\hline & $\mathrm{MXD}$ & Cattle & NA & $\begin{array}{l}\text { Efficacy increase (from } \\
55 \text { to } 91 \% \text { ) against IVM- } \\
\text { resistant Cooperia spp. }\end{array}$ & {$[113]$} \\
\hline \multicolumn{6}{|l|}{ Dosage levels } \\
\hline $\begin{array}{l}\mathrm{ABZ} \text { at } 15 \mathrm{mg} / \mathrm{kg}(3 \\
\text { times the dose) }\end{array}$ & $\mathrm{ABZ}$ & Sheep & $\begin{array}{l}\text { 7-fold ABZSO } \\
\text { plasma AUC } \\
\text { increase }\end{array}$ & $\begin{array}{l}\text { Efficacy increase (from } \\
16 \text { to } 59 \% \text { ) against highly } \\
\text { resistant } H \text {. contortus }\end{array}$ & {$[114,117]$} \\
\hline $\begin{array}{l}\text { IVM at } 1 \mathrm{mg} / \mathrm{kg}(5 \\
\text { times the dose) }\end{array}$ & IVM & Sheep & $\begin{array}{l}\text { 5-fold plasma AUC } \\
\text { increase }\end{array}$ & $\begin{array}{l}\text { Efficacy increase (from } \\
42 \text { to } 75 \% \text { ) against highly } \\
\text { IVM-resistant } H \text {. } \\
\text { contortus }\end{array}$ & {$[115]$} \\
\hline $\begin{array}{l}\text { MXD at } 0.4 \mathrm{mg} / \mathrm{kg} \\
\text { (double dose) }\end{array}$ & $\mathrm{MXD}$ & Sheep & $\begin{array}{l}\text { 2.44-fold increase of } \\
\text { drug accumulation } \\
\text { within adult } H \text {. } \\
\text { contortus }\end{array}$ & $\begin{array}{l}\text { Efficacy increase (from } \\
86 \text { to } 98 \% \text { ) against IVM- } \\
\text { resistant } H . \text { contortus }\end{array}$ & {$[116]$} \\
\hline
\end{tabular}

ABZ, albendazole; ABZSO, active ABZ suphoxide metabolite; FLBZ, flubendazole; OFZ, oxfendazole; IVM, ivermectin; MXD, moxidectin; AUC, area under the concentration versus time curve (systemic exposure). NA: no data available.

benzimidazole efficacy. Thus, in vivo interference with hepatic FMO-mediated and/or CYPdependent metabolism has resulted in pronounced modifications to the pharmacokinetic disposition and/or enhanced systematic availability of active benzimidazole molecules $[6,11]$. Moreover, improved efficacy against benzimidazole-resistant strains of Teladorsagia 
circumcincta and Haemonchus contortus has been shown after administration of fenbendazole with piperonyl butoxide (a CYP inhibitor) in sheep [12]. These observations clearly pointed out the practical relevance of interference with liver oxidative metabolism (Box 3), which may represent a useful tool to increase the efficacy of benzimidazole anthelmintics.

Genomic and transcriptomic studies revealed the expression of xenobiotic-metabolizing enzymes and drug-transport proteins within certain helminths such as $H$. contortus [13] and Fasciola hepatica [14]. Metabolism enzymes and transporters act as parasite defense mechanisms against 'environmental' chemical toxins generated by the host, and also protect them from their own waste metabolic products. Further, biochemical studies with subcellular fractions revealed that helminth parasites are able to metabolize certain benzimidazoles, such as flubendazole [15], albendazole [16], and triclabendazole [17]. In addition, it has been suggested that increased S-oxidation of albendazole in $\mathrm{H}$. contortus [16] and triclabendazole in $F$. hepatica $[17,18]$ may contribute to the overall resistance mechanism toward these anthelmintics. Thus, metabolic inhibitors may also decrease the rate of biotransformation of these drugs within parasites and could help to improve drug activity, as shown after coincubation of triclabendazole with metabolic inhibitors, such as methimazole [19], piperonyl butoxide [20], and ketoconazole [21].

\section{Modulation of Drug-Transport-Mediated Excretion}

The ATP-binding cassette (ABC) transporters use the energy of ATP hydrolysis to transport a wide variety of substrates out of cells against a concentration gradient, leading to a decreased intracellular concentration [22]. An important number of compounds extensively used in ruminant species are substrates and/or inhibitors of different efflux ABC transporters [23]. Those interactions are now considered as a key pharmacological issue with multiple therapeutic implications. P-glycoprotein (P-gp; see 'drug-transport proteins' in the glossary) has been the most studied cell transporter. Several in vivo and in vitro trials have been performed to assess the interaction of macrocyclic lactones and P-gp modulators [24,25].

The majority of studies on drug interactions mediated by ABC transporters have been addressed to modulate their activity, that is, increase absorption or delay the elimination of

Box 3. Modulation of Drug Metabolism and Transport-Mediated Excretion as Strategies to Optimize Anthelmintic Activity

Inhibitors of drug-metabolizing enzymes or transport proteins are useful pharmacological tools to increase the systemic exposure and efficacy of anthelmintic drugs. Increased susceptibility of resistant parasites could be expected as a consequence of enhanced levels of active anthelmintic molecules attained in host tissues and accumulated within target parasites. Different studies on the inhibition of the metabolism of the flukicidal triclabendazole and modulation of ivermectin excretion (Figure I) are powerful examples of this research area.

In vitro studies with sheep liver microsomes showed that both the FMO and CYP systems are involved in the S-oxidation of triclabendazole [8]. In addition, subcellular fractions of Fasciola hepatica were able to S-oxidize triclabendazole into its sulphoxide derivative, and this metabolic reaction was increased in resistant flukes [17]. Further in vitro assays revealed that different enzyme inhibitors (methimazole, piperonyl butoxide, ketoconazole) are able to delay triclabendazole metabolism in the host [8] as well as in F. hepatica subcellular fractions from both susceptible and resistant strains [17]. Pharmacokinetic trials showed increased systemic exposure of triclabendazole metabolites in sheep upon coadministration of the flukicidal drug with CYP inhibitors (piperonyl butoxide and ketoconazole) [11] (Figure I). Furthermore, morphologic studies have shown that coincubation of triclabendazole or its sulphoxide metabolite with metabolic inhibitors leads to greater disruption to tegument in triclabendazole-resistant flukes compared to that observed after adult fluke incubation with each anthelmintic molecule alone [19-21].

In vitro studies have demonstrated that P-gp plays a pivotal role in ivermectin elimination from ruminant hosts [119-121]. Moreover, overexpression of at least one Pgp isotype has been suggested as one of the mechanisms involved in ivermectin resistance in nematodes such as Haemonchus spp. [37,40,92,122], Teladorsagia circumcincta [40], and Cooperia oncophora [33]. In addition, P-gp inhibitors enhanced the in vitro activity of ivermectin against resistant larvae of those nematodes $[33,92]$ (Figure I). Different in vivo trials have shown increased ivermectin systemic exposure after its coadministration with P-gp-modulating agents such as verapamil [26], quercetin [91], loperamide [43], and itraconazole [28]. Similarly, increased efficacies against resistant Haemonchus contortus and Trichostrongy/us colubriformis (sheep) and Cooperia spp. (cattle) were observed when the P-gp substrate loperamide was coadministered with ivermectin [43]. Loperamide (an opiod derivative) induced relevant changes to the disposition kinetics of ivermectin in both species, enhancing their systemic exposure. 


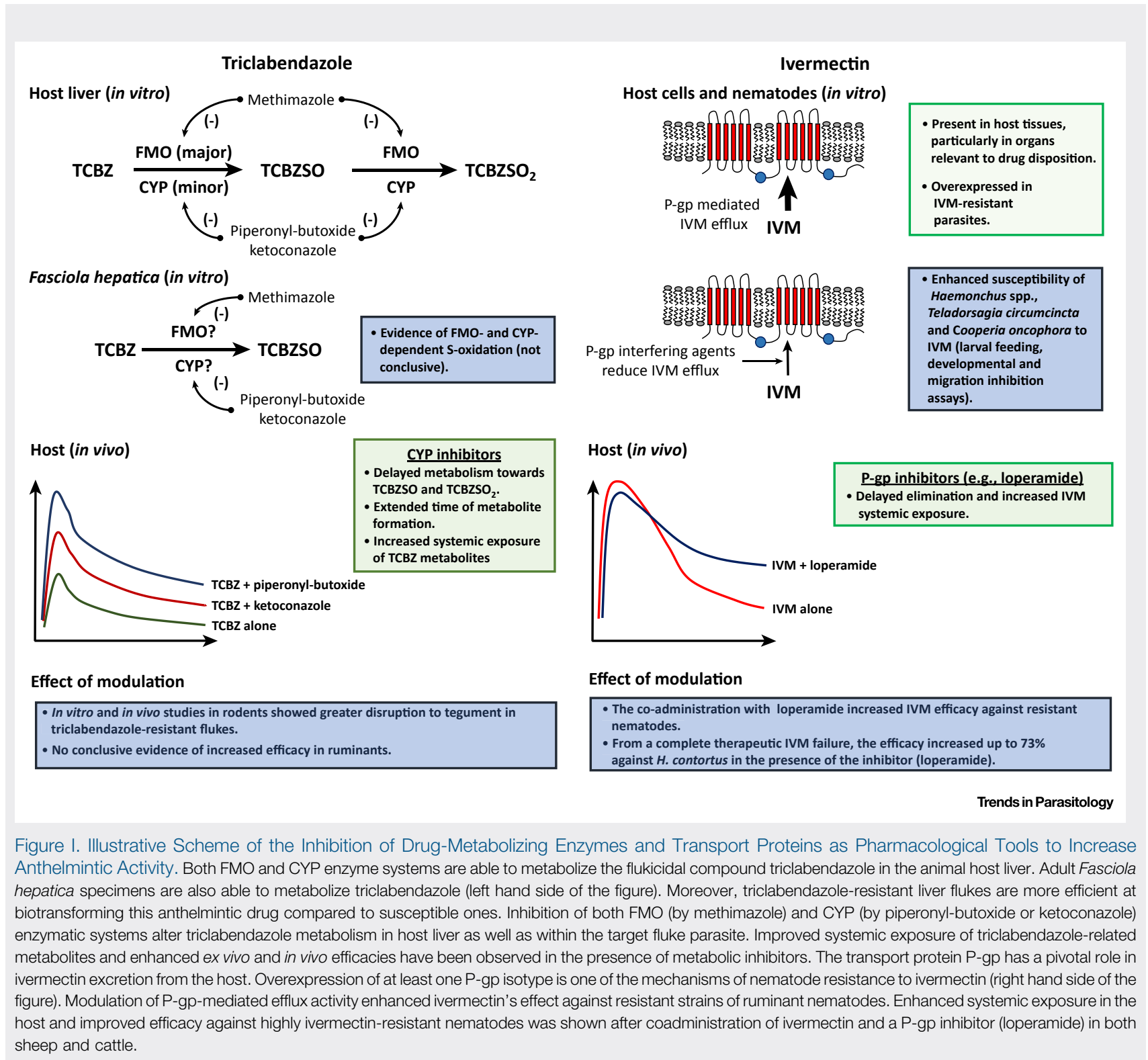

anthelmintic molecules. Changes to disposition kinetics and enhanced systemic exposure for ivermectin (IVM) and/or moxidectin have been shown after their coadministration with P-gp modulators, verapamil [26], loperamide [27], itraconazole [28], and ketoconazole [29]. Interference of Pgp-mediated drug excretion has also been shown following coadministration of two anthelmintic compounds. Ivermectin systemic exposure was markedly increased after its coadministration with triclabendazole (flukicidal) [30] and albendazole [31] in sheep.

The protein transporter P-gp has also been described in nematode parasites such as $H$. contortus [32] and Cooperia spp. [33]. Evidence supporting the involvement of P-gp in the genetic changes associated with resistance [34] and the identification of several P-gp sequences in the $\mathrm{H}$. contortus genome [35] are considered key issues in anthelmintic 
resistance. Modification of the pattern of P-gp expression (i.e., ivermectin-induced upregulation) was observed in resistant nematodes recovered from treated lambs [34,36]. Differential drug affinities by P-gp were also established. Moxidectin has a lower effect on the inhibition of P-gp transport than ivermectin $[37,38]$, which may explain the slower rate of resistance development to moxidectin compared to other avermectins in $H$. contortus $[37,38]$. Also, a marked induction of P-gps was observed in parasites exposed to different drugs. Several P-gp genes showed significantly higher transcription (up to 12-fold) in resistant $H$. contortus after $3 \mathrm{~h}$ exposure to ivermectin and levamisole. The exposure to both drugs also increased the activity of constitutive transport proteins in susceptible isolates [39].

Modulation of efflux transport (P-gp) accounts for enhanced drug exposure in the host. However, transport-related drug-drug interactions in parasite tissues may contribute to enhanced drug accumulation and efficacy in resistant worms. P-gp modulators (PSC833, verapamil, ketoconazole, pluronic 85) enhanced the sensitivity of larvae to ivermectin [40]. Verapamil also increased in vitro ivermectin activity against susceptible and resistant isolates of Cooperia spp. [33], and the third generation of P-gp modulators (tariquidar, zosuquidar, elacridar) have been shown to synergistically increase sensitivity to ivermectin [41]. The impact of in vivo modulation of drug transport on anthelmintic activity against field resistant nematodes has been assessed (Box 3). Attempts to reverse resistance were performed using the opioidderivative loperamide, which altered the disposition kinetics of both ivermectin and moxidectin, improving their therapeutic responses against resistant Cooperia spp. (cattle) [42] and tolerant Gl nematodes (sheep) [43]. Similarly, pluronic 85 drastically increased ivermectin efficacy against resistant $H$. contortus [44].

There is sound scientific evidence that modulation of P-gp-mediated excretion activity increases the systemic exposure of some anthelmintic drugs in the host. Additionally, this drug-drug interaction may also decrease the P-gp-mediated efflux overexpressed in resistant helminth parasites, which could explain the favourable therapeutic response against resistant nematodes observed in field trials. Further investigation is needed to discover potent and specific modulators that permit a reversion of the resistance mechanism in parasites without toxicity in the host.

\section{Combination of Anthelmintic Drugs from Different Chemical Groups \\ Pharmacological Rationale behind the Use of Drug Combinations}

There is a long history of chemotherapeutic agents with similar spectrums and different modes of action used in combination for treating the most dreadful diseases, including cancer [45], bacterial [46] and viral [47] infections. The combination strategy has been successful in achieving improved efficacy, decreased toxicity, and reduced development of drug resistance. In ruminants, nematodicidal combinations can be used to delay resistance development, to control specific dose-limiting species, and/or to manage existing field resistance $[48,49]$ (Figure 1). Available data demonstrate that the use of drug combinations, especially when they are introduced before resistance to all active ingredients included in the combination develops, will slow the development of resistance [49-53]. Several pharmaceutical formulations combining either two or three chemical entities are available in the market in some countries. Fixed products mainly combine molecules belonging to the benzimidazole, macrocyclic lactones, or imidazothiazole chemical groups. Additionally, a novel spiroindole compound (derquantel) has been combined with abamectin for use in sheep. Monepantel, the most recently introduced nematodicidal aminoacetonitrile derivative, is commercialized alone but its association with abamectin is under current consideration. 
Genetic variation within populations of Gl nematodes is unexpectedly large [2]. It is important to note that the higher the genetic diversity, the greater the likelihood that resistant alleles will be present. The rationale behind using drug combinations is based on the fact that individual worms may have a lower degree of resistance to a multiple component formulation (each chemical with a different mode of action/resistance) compared to that observed when a single anthelmintic molecule is used (Box 4). The resulting low number of surviving parasites with resistant genotypes would be diluted into the nematode population in refugia, and the resistant worms would take longer to become predominant. Modeling $[52,54,55]$ and empirical $[50,51]$ studies indicate that combined treatments are still effective in slowing the development of resistance even when the initial resistance to one component of the combination is high. Furthermore, a model simulation [55] suggested that when fitness costs associated with resistance increase, resistance develops more slowly. In the absence of an adequate level of refugia, the use of combinations has the potential to select for development of multiple drugresistant nematodes, reducing the range of anthelmintic options [56]. If parasite populations under refuge is high (contaminated pastures), animal reinfection will be also high and animal performance will be negatively affected; therefore, the frequency of anthelmintic treatments (selection pressure) will increase, favoring resistance development. Achieving a correct balance among nematode populations in refuge, worm burdens in grazing animals, and their productive performance is a complex challenge.

\section{Pharmaco-Parasitological Assessment of the Combined Use of Anthelmintics in Ruminants}

The occurrence of potential pharmacokinetic and/or pharmacodynamic interactions between drug components highlights the need for deeper pharmacology research to identify the advantages/disadvantages of the use of combined drug preparations for anthelmintic control in livestock (Figure 1).

\section{Pharmacokinetic Interactions}

The relationship among active drug concentrations in the bloodstream, those attained in parasite location tissues of the host, and their accumulation within target parasites (Box 1),

\section{Box 4. Rationale and Practical Advantages Derived from the Use of Combined Nematodicidal Treatments}

Rationale

The 'initial' parasite populations are genetically diverse [2], which leads to variation in the response to anthelmintic drugs. Thus, anthelmintic treatments provide a survival advantage for worms carrying resistance alleles [123]. The rationale for using combined anthelmintic treatments is illustrated in Figure I. The 'initial' population includes parasites susceptible to drugs named A and B (green-colored worms), worms resistant to either drug A (purple worms), to drug B (blue worms) or, at a lower frequency, to both anthelmintic drugs (red worms) (multiple resistant). Under this scenario, the use of combined treatments is supported by the fact that the only resistant genotypes which may survive are those simultaneously carrying genes for resistance to all the active ingredients. Thus, the use of anthelmintic combinations can slow the development of resistance [54]. Theoretically, worms resistant to drug A and those multiple resistant (to drugs A and B) will survive after treatment with drug $A$, contributing to the next generation. A similar situation could be expected after treatment with drug B. However, when drugs $A$ and $B$ are used in combination, worms surviving one of the compounds could be killed by the other, with only a low proportion of multiple resistant parasites surviving. Achieving the highest possible efficacy is a powerful argument for using anthelmintic combinations; since fewer resistant parasites will survive treatment, the diluting effect with susceptible unselected parasites in refugia will be greater, and thus the development of resistance may be slowed [124,125].

\section{Practical}

An example of potential advantages derived from the use of anthelmintics in combination on a commercial cattle farm is shown in Figure I. After a combined treatment of ivermectin (IVM) + ricobendazole (RBZ), a therapeutic additive effect was observed, with overall anthelmintic efficacies of 48\% (IVM alone), $94 \%$ (RBZ alone), and $98 \%$ (IVM + RBZ). Additionally, the excretion of eggs to the pasture was found to be much lower following the combined treatment. At day 15 post-treatment, the highest number of excreted eggs was exhibited by the group treated with IVM (16 million), followed by the RBZ group ( 2 million), and finally the combined IVM + RBZtreated calves ( 0.6 million) [53]. Therefore, the use of the combination resulted in lower pasture contamination than the treatment with RBZ alone. Thus, the field situation demonstrated that the combined treatment achieved the highest efficacy, minimizing pasture contamination with resistant surviving worms, and thus favoring dilution with unselected genotypes. In fact, the development of anthelmintic resistance would be delayed. 


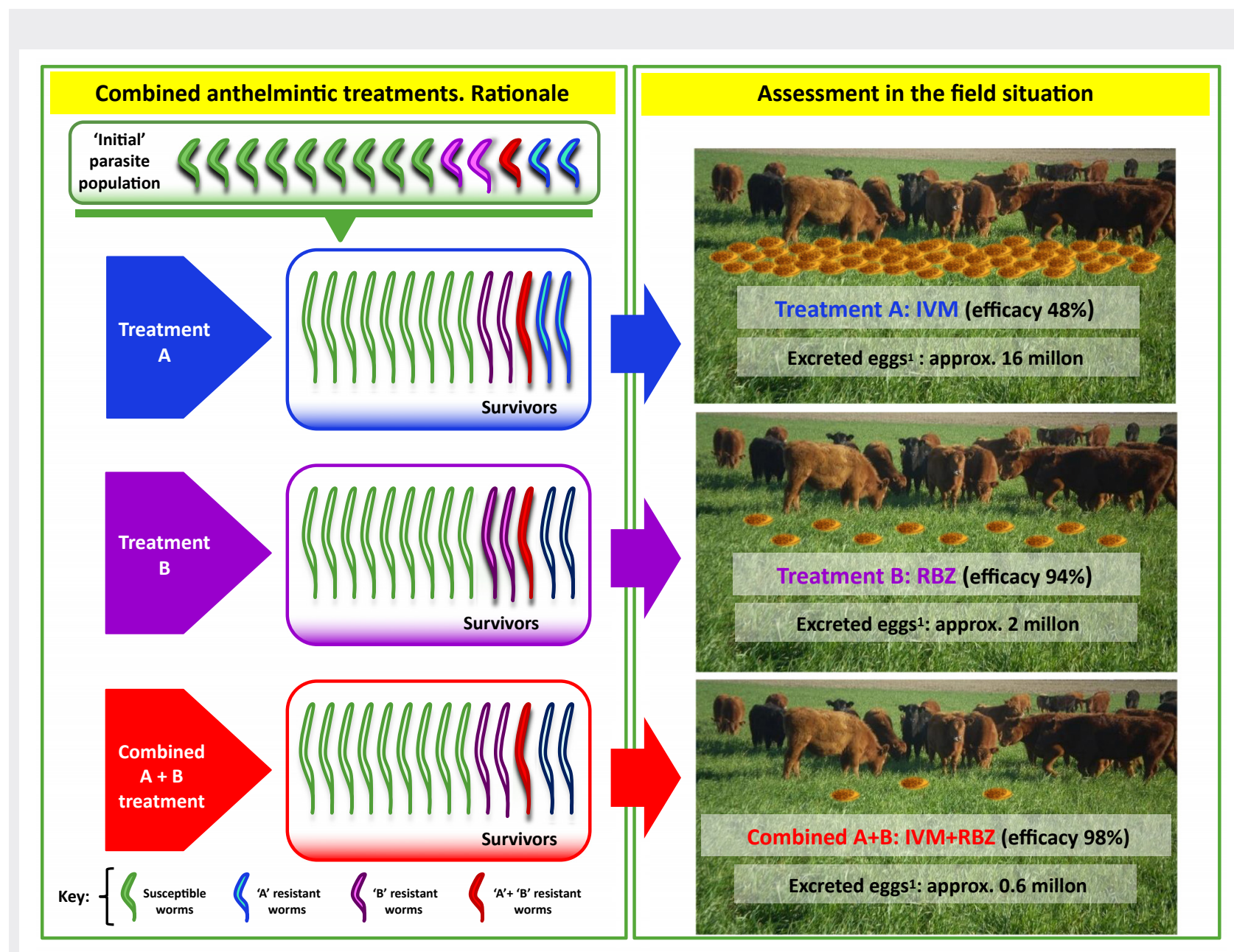

Trends in Parasitology

Figure I. Illustration of the Rationale behind the Use of Combined Anthelmintic Treatments. Data from a field trial assessment is shown on the right hand side of the figure. The therapeutic response following the administration of ivermectin (IVM) and ricobendazole (RBZ) given both separately and coadministered to calves parasitized with gastrointestinal nematodes resistant to IVM and susceptible to RBZ [53] is schematically illustrated. Excreted eggs ${ }^{1}$ : Sum of eggs excreted per day (day 15 post-treatment) by the 15 animals included in each experimental group.

is now well established. Drug interactions occurring during absorption and metabolism/transport/excretion processes may affect the anthelmintic response. Positive pharmacokinetic interactions between combined nematodicidal drugs have been observed in lambs [31,57]. Although most combined treatments in cattle did not show the existence of drug pharmacokinetic interactions (Table 1), the oral coadministration of abamectin + levamisole [58] resulted in greater abamectin availability in the animals. Preferably, the actives in the combination should have similar persistence in the organism to ensure that they are both present together throughout the duration of the treatment [56]. In contrast, if their disposition patterns are different, one compound may be present and the other absent at a given time, which allows some parasites that are resistant to one component to survive treatment, thereby increasing the proportion of resistant parasites. However, this situation is not different from what would be experienced when each constituent active is used alone. Assessment of both the positive and negative (adverse) impacts of pharmacokinetic interactions occurring between combined 
Table 1. Summary of in vivo trials Assessing Anthelmintic Combined Treatments against Gastrointestinal Nematodes in Cattle

\begin{tabular}{|c|c|c|c|c|c|c|c|c|c|c|c|}
\hline \multirow{3}{*}{$\begin{array}{l}\text { Anthelmintic } \\
\text { combination }\end{array}$} & \multirow[t]{3}{*}{ Treatment } & \multirow[t]{3}{*}{ Route } & \multicolumn{3}{|c|}{ Parasitological assessment } & \multicolumn{5}{|c|}{ Pharmacological assessment } & \multirow[t]{3}{*}{ Refs } \\
\hline & & & \multirow{2}{*}{$\begin{array}{l}\text { Observed } \\
\text { efficacy }(\%)\end{array}$} & \multirow{2}{*}{$\begin{array}{l}\text { Expected } \\
\text { efficacy }(\%)\end{array}$} & \multirow[t]{2}{*}{ PD interaction } & \multicolumn{2}{|c|}{ Systemic exposure expressed as AUC } & \multicolumn{2}{|r|}{ Cmax } & \multirow[t]{2}{*}{ PK interaction } & \\
\hline & & & & & & Alone & Combination & Alone & Combination & & \\
\hline \multirow[t]{3}{*}{$A B A+L_{E V}{ }^{C}$} & ABA & Oral & 90.5 & & & 104.3 & 144.9 & 35.9 & 53.0 & $\begin{array}{l}\text { Positive } \\
\text { interaction }\end{array}$ & \multirow[t]{3}{*}{ [58] } \\
\hline & LEV & Oral & 96.2 & & & n.d. & n.d. & n.d. & n.d. & n.d. & \\
\hline & $A B A+L E V$ & Oral & 99.6 & 99.6 & Additive & & & & & & \\
\hline \multirow[t]{3}{*}{$\mathrm{IVM}+\mathrm{RBZ}$} & IVM & SC & 48.0 & & & 348 & 390 & 46.3 & 47.9 & No interaction & \multirow[t]{3}{*}{ [53] } \\
\hline & RBZ & SC & 94.0 & & & 10.8 & 10.9 & 0.85 & 0.77 & No interaction & \\
\hline & $\mathrm{IVM}+\mathrm{RBZ}$ & SC & 98.0 & 96.8 & Additive & & & & & & \\
\hline \multirow[t]{3}{*}{ RBZ + LEV } & $\mathrm{RBZ}$ & SC & 96.0 & & & 8.20 & 10.1 & 0.64 & 0.84 & No interaction & \multirow[t]{3}{*}{ [97] } \\
\hline & LEV & SC & 99.0 & & & 7.66 & 9.07 & 1.43 & 1.51 & No interaction & \\
\hline & RBZ + LEV & $\mathrm{SC}$ & 100 & 99.9 & Additive & & & & & & \\
\hline \multirow[t]{3}{*}{$M X D+L^{\prime} V^{d}$} & MXD & SC & 74.3 & & & n.d. & n.d. & n.d. & n.d. & n.d. & \multirow[t]{3}{*}{ [98] } \\
\hline & LEV & SC & 79.3 & & & n.d. & n.d. & n.d. & n.d. & n.d. & \\
\hline & MXD + LEV & SC & 98.1 & 94.6 & Additive? & & & & & & \\
\hline \multirow[t]{3}{*}{$M X D+R B Z^{d}$} & MXD & SC & 74.3 & & & n.d. & n.d. & n.d. & n.d. & n.d. & \multirow[t]{3}{*}{ [98] } \\
\hline & RBZ & SC & 37.5 & & & n.d. & n.d. & n.d. & n.d. & n.d. & \\
\hline & $M X D+R B Z$ & SC & 88.4 & 83.9 & Additive? & & & & & & \\
\hline \multirow[t]{3}{*}{$\mathrm{RBZ}+\mathrm{CLO}^{\mathrm{d}}$} & RBZ & $\mathrm{SC}$ & 37.5 & & & n.d. & n.d. & n.d. & n.d. & n.d. & \multirow[t]{3}{*}{ [98] } \\
\hline & CLO & Oral & 49.6 & & & n.d. & n.d. & n.d. & n.d. & n.d. & \\
\hline & $\mathrm{RBZ}+\mathrm{CLO}$ & $\mathrm{SC}+$ Oral & 60.2 & 68.5 & Indifference & & & & & & \\
\hline
\end{tabular}


Table 1. (continued)

\begin{tabular}{|c|c|c|c|c|c|c|c|c|c|c|c|}
\hline \multirow{3}{*}{$\begin{array}{l}\text { Anthelmintic } \\
\text { combination }\end{array}$} & \multirow[t]{3}{*}{ Treatment } & \multirow[t]{3}{*}{ Route } & \multicolumn{3}{|c|}{ Parasitological assessment } & \multicolumn{5}{|c|}{ Pharmacological assessment } & \multirow[t]{3}{*}{ Refs } \\
\hline & & & \multirow{2}{*}{$\begin{array}{l}\text { Observed } \\
\text { efficacy }(\%)\end{array}$} & \multirow{2}{*}{$\begin{array}{l}\text { Expected } \\
\text { efficacy }(\%)\end{array}$} & \multirow[t]{2}{*}{ PD interaction } & \multicolumn{2}{|c|}{ Systemic exposure expressed as AUC } & \multicolumn{2}{|r|}{ Cmax } & \multirow[t]{2}{*}{ PK interaction } & \\
\hline & & & & & & Alone & Combination & Alone & Combination & & \\
\hline \multirow[t]{3}{*}{$\mathrm{DRM}+\mathrm{CLO}^{d}$} & DRM & SC & 6.72 & & & n.d. & n.d. & n.d. & n.d. & n.d. & \multirow[t]{3}{*}{ [98] } \\
\hline & CLO & Oral & 49.6 & & & n.d. & n.d. & n.d. & n.d. & n.d. & \\
\hline & $\mathrm{DRM}+\mathrm{CLO}$ & $\mathrm{SC}+$ Oral & 65.5 & 52.9 & Synergism? & & & & & & \\
\hline \multirow[t]{3}{*}{$\mathrm{DRM}+\mathrm{FBZ}^{\mathrm{d}}$} & DRM & SC & 6.72 & & & n.d. & n.d. & n.d. & n.d. & n.d. & \multirow[t]{3}{*}{ [98] } \\
\hline & FBZ & Oral & 89.2 & & & n.d. & n.d. & n.d. & n.d. & n.d. & \\
\hline & $\mathrm{DRM}+\mathrm{FBZ}$ & $\mathrm{SC}+$ Oral & 92.1 & 89.9 & Additive & & & & & & \\
\hline \multirow[t]{3}{*}{$\mathrm{LEV}+\mathrm{CLO}^{\mathrm{d}}$} & LEV & SC & 79.3 & & & n.d. & n.d. & n.d. & n.d. & n.d. & \multirow[t]{3}{*}{ [98] } \\
\hline & CLO & Oral & 49.6 & & & n.d. & n.d. & n.d. & n.d. & n.d. & \\
\hline & $\mathrm{DRM}+\mathrm{CLO}$ & $\mathrm{SC}+$ Oral & 88.6 & 89.5 & Additive & & & & & & \\
\hline
\end{tabular}

ABA, abamectin; LEV, levamisole; IVM, ivermectin; RBZ, ricobendazole; MXD, moxidectin; CLO, closantel; DRM, doramectin; FBZ, fenbendazole; SC, subcutaneous; PD, pharmacodynamic; PK, pharmacokinetic; AUC, area under the plasma concentration versus time curve (expressed as either $\mu \mathrm{g} \cdot \mathrm{h} / \mathrm{ml}$ or $\mathrm{ng} . \mathrm{d} / \mathrm{mll}$ ); Cmax, peak plasma concentration (expressed as $\mu \mathrm{g} / \mathrm{ml}$ or $\mathrm{ng} / \mathrm{ml}$ ). $\mathrm{n} . \mathrm{d} . \mathrm{n}$ not determined.

abserved anthelmintic efficacy of the different treatments assessed by the faecal egg count reduction test.

${ }^{5}$ Expected efficacy assuming additive anthelmintic effects [49].

The results of the observed efficacy are presented as the mean across the ten farms included in the trial.

The results of the observed efficacy are presented as the mean across the four farms included in the trial. 
anthelmintic molecules needs to be elucidated before recommending the use of nematodicidal drugs in combination.

\section{Pharmacodynamic Interactions}

The differential mode of actions exhibited by benzimidazoles, macrocyclic lactones and imidazothiazoles may potentially induce a synergistic effect when they are coadministered. Several in vitro studies demonstrated the synergistic activity of different nematodicidal drugs used in combination $[59,60]$. Evidence of synergist action has been also observed under in vivo conditions, where fenbendazole and levamisole were coadministered in goats parasitized with resistant GI nematodes [61]. Production benefits for cattle parasitized with resistant nematodes have been obtained with the combined use of doramectin and albendazole [62]. However, most cases of in vivo pharmacodynamic interactions between nematodicidal drugs appear to be limited to an additive effect both in sheep [63-65] and cattle (Table 1).

It is always important to note that a combination product may promote multidrug resistance if its component drugs act on the same parasite gene or share a common resistance mechanism. In fact, recent work suggests that resistance to IVM can be selected by previous exposure to benzimidazole anthelmintics. It was hypothesized that genetic mechanisms related to benzimidazole resistance could also contribute to P-gp overexpression leading to IVM resistance [66]. However, it is still unclear if this 'cross resistance' is sufficient to nullify the benefits of administering these anthelmintics in combination.

The use of combinations in resistance management is not a panacea. Sustainable parasite control should be customized to individual farms through the design of sound parasite-control practices for each specific farm according to in situ obtained parasitological information. Following those critical premises, nematodicidal combinations may remain as a sustainable tool for parasite control in livestock.

\section{Bioactive Natural Products: Assessment of Their Potential for Combined Use with Anthelmintic Drugs \\ Anthelmintically Active Phytochemicals}

Plants produce a variety of substances known as secondary metabolites, which play an important role in plant defense mechanisms [67]. The bioactive phytochemical terpenes, condensed tannins, and flavonoids are plant secondary metabolites with well established anthelmintic properties and a growing relevance in ruminants' helminth control.

Terpenes are structurally diverse and the most abundant group of plant volatiles. Terpenes are present in different plant organs and are used to treat several human and animal diseases. These bioactive compounds are synthesized as essential oils, which is a blend of different terpenes, mainly monoterpenes [68,69]. The essential oils and their monoterpenes exhibit notable anthelmintic properties both in vitro $[70,71]$ and in vivo $[70,72,73]$. Chicory-based diets (rich in sesquiterpene lactones) induced significant reductions in Ostertagia ostertagi worm burdens in cattle $[74,75]$. There is limited information on the nematodicidal activity of monoterpenes in combination with other natural or synthetic compounds. However, there are several studies reporting promising results for the combination of natural and synthetic compounds in the control of fungi, bacteria, and ticks $[76,77]$. It has been proposed that inhibition of biochemical targets such as acetylcholinesterase [78], GABA [79], and tyramine receptors [80] may account for the anthelmintic action of terpenes. Terpenes also interact with glutamategated chloride channels [81] and P-gp [82]. However, although several potential mechanisms 
of action have been investigated, the specific mechanism supporting their anthelmintic activity is still unknown.

Both the anthelmintic and nutritional effects of condensed tannins vary according to a number of factors, including their concentration and chemical structures, physiological state, diet of the ruminant host, and target Gl nematodes [83]. Condensed tannins may act directly on nematodes (anthelmintic effect) or indirectly by improving the nutritional status and host's immune response against infection [84]. The direct anthelmintic action is based on the formation of tannin-protein complexes. The cuticle and excretion/secretion products of different parasitic life stages contain a variety of proteins. The tannin-nematode protein complexes may alter some mechanisms necessary for parasite survival (L3 cuticle lost, feeding, motility, fecundity, egg hatching, and a range of enzymatic-mediated biochemical functions) [83,85-87]. The most effective immunological responses against infections occur due to a greater availability of proteins to the host caused by the bypass effect, in which proteins bound to tannins are not degraded in the rumen, increasing the rate of digestibility and protein degradation at the gut level [88].

Plant flavonoids are a class of widely distributed phenolic compounds [89]. Flavonoids are P-gp modulators with high in vitro activity against $H$. contortus [24,90]. The identification of natural compounds that could either modulate drug efflux from the parasite or serve as synergists to potentiate the activity of synthetic anthelmintics is an attractive challenge for research. Results obtained from plant extracts rich in flavonoids are extremely encouraging either for potential development of new compounds or to identify modulator agents capable of extending the lifespan of existing anthelmintics [91,92].

Bioactive Phytochemicals as Tools to Complement Current Anthelmintic Therapy

The search for alternatives to the traditional anthelmintics requires urgent attention. The identification of natural bioactives with potential to be used as complementary anthelmintic tools is challenging [5]. The combined use of bioactive monoterpenes with synthetic anthelmintics may be optimal to achieve synergist activity at different sites of action [93]. Potential additive or synergistic effects between natural and synthetic compounds should be more fully evaluated against resistant worms. Synergism between monoterpenes and anthelmintics has been demonstrated [79]. However, further work is needed to determine potential kinetic/dynamic interferences between natural bioactives and the drugs to be combined (Figure 1).

Taninipherous plants are available to ruminants in nature as, hay, pellets, etc. Tannins have the ability to complex with several molecules, which could either reduce the Gl absorption of synthetic anthelmintics, decreasing their systemic availability and efficacy [94], or enhance anthelmintic activity through the inhibition of detoxifying enzymes [85,87] (Figure 1). Evidence has also shown that the association of flavonoids with condensed tannins [95], moxidectin [91] or ivermectin [92] reaches a synergistic effect of great pharmacological relevance. However, conclusive in vivo experiments showing beneficial efficacy after the combination of flavonoids and ivermectin/moxidectin are not yet available. A cautious pharmacological assessment should be performed to take full advantage of the control strategy based on either the use of phytochemicals alone [96] or their combined administration with existing/novel anthelmintics (Figure 1, Key Figure).

A huge challenge to increasing reliance on non-traditional means of parasite control is the high cost of achieving a standardized natural product. However, the well-demonstrated synergistic 


\section{Strategies to optimize the use of traditional and novel anthelmintic compounds}

\begin{tabular}{|c|c|}
\hline $\begin{array}{l}\text { 1. Pharmacokinetic } \\
\text { optimization }\end{array}$ & $\begin{array}{l}\text { The pharmacokinetic-based enhancement of parasite exposure has been } \\
\text { investigated as a main pharmacological tool to optimize drug activity against } \\
\text { resistant parasites. }\end{array}$ \\
\hline $\begin{array}{l}\text { Enhanced parasite } \\
\text { exposure }\end{array}$ & $\begin{array}{l}\text { Enhanced systemic exposure results in increased drug concentrations } \\
\text { within target worms carrying resistant genes. } \\
\text { Increased drug exposure may be a useful strategy for killing heterozygous } \\
\text { resistant worms during the earliest phases of resistance development. } \\
\text { However, no therapeutic advantage may be obtained when homozygous } \\
\text { resistant genotypes are predominant within the parasite population. }\end{array}$ \\
\hline $\begin{array}{l}\text { 2. Combination of different } \\
\text { chemical groups }\end{array}$ & $\begin{array}{l}\text { The combination of two (or more) synthetic anthelmintic drugs with } \\
\text { different sites/modes of action/resistance is a useful pharmacological tool } \\
\text { when resistant nematodes are present. }\end{array}$ \\
\hline $\begin{array}{l}\text { Alternative/different } \\
\text { sites/modes of action }\end{array}$ & $\begin{array}{l}\text { Individual worms may have a lower degree of resistance to a multiple } \\
\text { component (combined) formulation compared to that observed after the } \\
\text { use of a single anthelmintic active ingredient. } \\
\text { Anthelmintic combinations can be used for delaying the appearance of } \\
\text { resistance, for specific targeting of dose-limiting species and/or for } \\
\text { management of existing resistance. }\end{array}$ \\
\hline $\begin{array}{l}\text { 3. Combined use of } \\
\text { synthetic anthelmintics and } \\
\text { bioactive phytochemicals }\end{array}$ & $\begin{array}{l}\text { The use of bioactive natural products as complementary tools to existing } \\
\text { synthetic anthelmintic drugs has shown promising results (i.e., synergist } \\
\text { anthelmintic activity of terpenes with albendazole and/or ivermectin). } \\
\text { Changes in anthelmintics systemic availability: (a) tannin-induced decrease } \\
\text { in gastrointestinal absorption (ivermectin reduced exposure), (b) flavonoid- } \\
\text { induced metabolic interference (benzimidazole enhanced exposure). }\end{array}$ \\
\hline $\begin{array}{l}\text { Synergistic activity acting at } \\
\text { different sites/modes of action }\end{array}$ & $\begin{array}{l}\text { Further work is required to assess: (a) drug/bioactive phytochemical } \\
\text { combined efficacy responses, (b) mode of anthelmintic action and basis of } \\
\text { the synergist activity, (c) chemical interactions affecting drug } \\
\text { absorption/metabolism/excretion, (d) development of alternative } \\
\text { formulations/routes of administration, (e) in vivo efficacy testing. }\end{array}$ \\
\hline
\end{tabular}

Figure 1. These strategies are based on either: (1) enhanced parasite exposure to the active ingredient, (2) simultaneous targeting at more than one site of action, or (3) achieving synergistic activity at different sites of action after the combined use of a synthetic anthelmintic drug and bioactive natural products. Key explanatory comments are shown on the right hand side of the scheme.

effects occurring between certain natural and synthetic compounds may allow for the use of lower concentrations and/or increase the efficiency of synthetic anthelmintics in resistant populations. Any type of chemical combination should always be guided by a deep pharmacological understanding of the underlying mechanisms in order to optimize its therapeutic use to control resistant nematodes. 


\section{Concluding Remarks}

Anthelmintic resistance in animal-pathogenic helminths has been spreading in prevalence and severity. Considering the increasing development of anthelmintic resistance, the use of pharmacology-based information is critical to design successful strategies for future livestock parasite control. Different pharmacokinetic-based approaches to enhance parasite exposure, and the use of combinations of drugs from different chemical families, have been proposed as valid strategies to delay the development of anthelmintic resistance (Figure 1). The activity of the recently developed anthelmintics (i.e., monepantel, derquantel) against multidrug-resistant isolates, which is based on novel modes of action, is a highly favorable element. However, the integrated use of pharmacology-based information for both existing and novel molecules is critical for the design of successful strategies for the future of parasite control. Modern technologies will likely contribute with some leading products in the field of diagnostic or drug discovery. Meanwhile, further pharmaco-parasitological integrated work, supported by significant advances made in parasite genomics (see Outstanding Questions) is required to generate the basic scientific knowledge necessary to optimize drug action and to preserve active ingredients as useful and sustainable tools for parasite control in livestock animals. The identification/development of complementary/alternative measures of parasite control in livestock animals is also required.

\section{Acknowledgments}

The authors appreciate the contribution of their coworkers to the outline and execution of the research whose results are summarised here. Research at the Laboratorio de Farmacología, CIVETAN, CONICET-CICPBA-UNCPBA is supported by the Agencia Nacional de Promoción Científica y Tecnológica, Universidad Nacional del Centro Pcia. de Buenos Aires and Consejo Nacional de Investigaciones Científicas y Técnicas (all from Argentina). Research at the Laboratorio de Controle de Parasitos, UFMA, is supported by the Fundação de Amparo ao Desenvolvimento Científico e Tecnológico do Maranhão and Conselho Nacional de Pesquisa e Desenvolvimento Científico from Brazil.

\section{References}

1. Waller, P. (2006) Sustainable nematode parasite control strategies for ruminant livestock by grazing management and biological control. Anim. Feed Sci. Technol. 126, 277-289

2. Geary, T. et al. (1999) Frontiers in anthelmintic pharmacology. Vet. Parasitol. 84, 275-295

3. Lanusse, C. and Prichard, R. (1993) Relationship between pharmacological properties and clinical efficacy of ruminant anthelmintics. Vet. Parasitol. 49, 123-158

4. Leathwick, D. and Luo, D. (2017) Managing anthelmintic resistance - variability in the dose of drug reaching the target worms influences selection for resistance? Vet. Parasitol. 243, 29-35

5. Lanusse, C. et al. (2014) Pharmacological knowledge and sustainable anthelmintic therapy in ruminants. Vet. Parasitol. 204, 18-33

6. Lanusse, C. and Prichard, R. (1993) Clinical pharmacokinetics and metabolism of benzimidazole anthelmintics in ruminants. Drug Metabol. Rev. 25, 235-279

7. Virkel, G. et al. (2004) Comparative hepatic and extrahepatic enantioselective sulfoxidation of albendazole and fenbendazole in sheep and cattle. Drug Metab. Dispos. 32, 536-544

8. Virkel, G. et al. (2006) Assessment of the main metabolism pathways for the flukicidal compound triclabendazole in sheep. J. Vet. Pharmacol. Ther. 29, 213-223

9. Alvarez, L. et al. (2000) Uptake of albendazole and albendazole sulphoxide by Haemonchus contortus and Fasciola hepatica in sheep. Vet. Parasitol. 94, 75-89

10. Lubega, G. and Prichard, R. (1991) Interaction of benzimidazole anthelmintics with Haemonchus contortus tubulin: binding affinity and anthelmintic efficacy. Exp. Parasitol. 73, 202-213
11. Virkel, G. et al. (2009) Inhibition of cytochrome P450 activity enhances the systemic availability of triclabendazole metabolites in sheep. J. Vet. Pharmacol. Ther. 32, 79-86

12. Benchaoui, H. and McKellar, Q. (1996) Interaction between fenbendazole and piperonyl butoxide: pharmacodynamic implications. J. Pharm. Pharmacol. 48, 753-759

13. Laing, R. et al. (2013) The genome and transcriptome of Haemonchus contortus, a key model parasite for drug and vaccine discovery. Genome Biol. 14, R88

14. Cwiklinski, K. et al. (2015) The Fasciola hepatica genome: gene duplication and polymorphism reveals adaptation to the host environment and the capacity for rapid evolution. Genome Biol. $16,71-84$

15. Vokral, I. et al. (2012) The metabolism of flubendazole and the activities of selected biotransformation enzymes in Haemonchus contortus strains susceptible and resistant to anthelmintics. Parasitology 139, 1309-1316

16. Vokrál, I. et al. (2013) Biotransformation of albendazole and activities of selected detoxification enzymes in Haemonchus contortus strains susceptible and resistant to anthelmintics. Vet. Parasitol. 196, 373-381

17. Alvarez, L. et al. (2005) Altered drug influx/efflux and enhanced matabolic activity in triclabendazole resistant liver flukes. Parasitology 131, 501-510

18. Robinson, M. et al (2004) The comparative metabolism of triclabendazole sulphoxide by triclabendazole-susceptible and triclabendazole- resistant Fasciola hepatica. Parasitol. Res. 92 205-210

19. Devine, C. et al. (2009) Effect of the metabolic inhibitor, methi mazole on the drug susceptibility of a triclabendazole-resistant isolate of Fasciola hepatica. Parasitology 136, 183-192

\section{Outstanding Questions}

Valid strategies to improve parasite control in livestock animals (enhanced drug exposure, drug combinations, bioactive natural products) have been identified. Could these experimentally observed therapeutic benefits be transferred into sustainable parasite control under field conditions? What will be their 'best' or 'more rationale' use to be introduced into control programs?

How can the favorable anthelmintic synergistic effects of drug combinations be optimized at the farm level? What would be a reasonable rotation scheme to extend the lifespan of these advantageous drug mixtures?

Phytochemicals offer a relevant opportunity for parasite control in livestock. How should they be used? As single natural products or combined with available anthelmintic drugs? If so, what will be the risk of pharmacochemical interactions affecting their anthelmintic therapeutic response?

Suitable research strategies have been identified as alternative measures of parasite control (selection of resistant animals, vaccine development, integrated farming, extended refugia, biological control, etc.). Could we provide a valid complementary (alternative) parasite-control measure to be applied under field conditions in the short term?

Drug repurposing has acquired specia relevance in several therapeutic fields. Could the use of old drugs for new indications be a valid strategy to control resistant nematodes?

Improved diagnosis is critical for helminth control under the current drug resistance scenario. Will genetic markers of drug resistance be available for use in the field in the near future?

Could genomic-assisted drug discovery or any other screening technologies come up with some novel molecules active against multiresistant parasites?

Could all the pharmaco-parasitological scientific knowledge that emerged 
20. Devine, C. et al. (2011) Piperonyl butoxide enhance triclabendazole action against triclabendazole-resistant Fasciola hepatica. Parasitology 138, 224-236

21. Devine, C. et al. (2012) Potentiation of triclabendazole action in vivo against a triclabendazole-resistant isolate of Fasciola hepatica following its co-administration with the metabolic inhibitor, ketoconazole. Vet. Parasitol. 84, 37-47

22. Bugde, P. et al. (2017) The therapeutic potential of targeting $\mathrm{ABC}$ transporters to combat multi-drug resistance. Expert Opin. Ther. Targets 21, 511-530

23. Virkel, G. et al. (2018) Role of ABC transporters in veterinary medicine: pharmaco-toxicological implications. Curr. Med. Chem. Published online February 25, 2018. http://dx.doi.org/ 10.2174/0929867325666180201094730

24. Lespine, A. et al. (2012) P-glycoproteins and other multidrug resistance transporters in the pharmacology of anthelmintics: prospects for reversing transport-dependent anthelmintic resistance. Int. J. Parasitol. Drugs Drug Resist. 2, 58-75

25. Lifschitz, A. et al. (2012) Macrocyclic lactones and cellular transport-related drug interactions: a perspective from in vitro assays to nematode control in the field. Curr. Pharm. Biotechnol. 13, 912-923

26. Molento, M. et al. (2004) Influence of verapamil on the pharmacokinetics of the antiparasitic drugs ivermectin and moxidectin in sheep. Parasitol. Res. 92, 121-127

27. Lifschitz, A. et al. (2002) Loperamide-induced enhancement of moxidectin availability in cattle. J. Vet. Pharmacol. Ther. 25, $111-120$

28. Ballent, M. et al. (2007) Involvement of P-glycoprotein on ivermectin kinetic behaviour in sheep: itraconazole-mediated changes on gastrointestinal disposition. J. Vet. Pharmacol. Ther. 30, 242-248

29. Alvinerie, M. et al. (2008) Ketoconazole increases the plasma levels of ivermectin in sheep. Vet. Parasitol. 157, 117-122

30. Lifschitz, A. et al. (2009) Combined use of ivermectin and triclabendazole in sheep: in vitro and in vivo characterisation of their pharmacological interaction. Vet. J. 182, 261-268

31. Alvarez, L. et al. (2008) Evaluation of the interaction between ivermectin and albendazole following their combined use in lambs. J. Vet. Pharmacol. Ther. 31, 230-239

32. Sangster, N. et al. (1999) Haemonchus contortus: sequence heterogeneity of internucleotide binding domains from p-glycoproteinsand an association with avermectin/milbemycin resistance. Exp. Parasitol. 91, 250-257

33. Demeler, J. etal. (2013) Potential contribution of P-glycoproteins to macrocyclic lactone resistance in the cattle parasitic nematode Cooperia oncophora. Mol. Biochem. Parasitol. 188, 10-19

34. Prichard, R. and Roulet, A. (2007) ABC transporters and $\beta$-tubulin in macrocyclic lactone resistance: prospects for marker development. Parasitology 134, 1123-1132

35. Williamson, S. and Wolstenholme, A. (2012) P-glycoproteins of Haemonchus contortus: development of real-time PCR assays for gene expression studies. J. Helminthol. 86, 202-208

36. Lloberas, M. et al. (2013) Comparative tissue pharmacokinetics and efficacy of moxidectin, abamectin and ivermectin in lambs infected with resistant nematodes: impact of drug treatments on parasite P-glycoprotein expression. Int. J. Parasitol. Drugs Drug Resist. 3, 20-27

37. Godoy, P. et al. (2015) Characterization of Haemonchus contortus P-glycoprotein-16 and its interaction with the macrocyclic lactone anthelmintics. Mol. Biochem. Parasitol. 204, 11-15

38. Godoy, P. et al. (2016) Characterisation of P-glycoprotein-9.1 in Haemonchus contortus. Parasites Vectors 9, 52

39. Raza, A. et al. (2016) Effects of in vitro exposure to ivermectin and levamisole on the expression patterns of $A B C$ transporters in Haemonchus contortus larvae. Int. J. Parasitol. Drugs Drug Resist. 6, 103-115

40. Bartley, D. et al. (2009) P-glycoprotein interfering agents potentiate ivermectin susceptibility in ivermectin sensitive and resistant isolates of Teladorsagia circumcincta and Haemonchus contortus. Parasitology 136, 1081-1088

41. Raza, A. et al. (2015) Effects of third generation P-glycoprotein inhibitors on the sensitivity of drug-resistant and-susceptible solates of Haemonchus contortus to anthelmintics in vitro. Vet. Parasitol. 211, 80-88

42. Lifschitz, A. et al. (2010) Cattle nematodes resistant to macrocyclic lactones: comparative effects of P-glycoprotein modulation on the efficacy and disposition kinetics of ivermectin and moxidectin. Exp. Parasitol. 125, 172-178

43. Lifschitz, A. et al. (2010) Interference with P-glycoprotein improves ivermectin activity against adult resistant nematodes in sheep. Vet. Parasitol. 172, 291-298

44. Bartley, D. et al. (2012) Influence of Pluronic 85 and ketoconazole on disposition and efficacy of ivermectin in sheep infected with a multiple resistant Haemonchus contortus isolate. Vet. Parasitol. 187, 464-472

45. Humphrey, R. et al. (2011) Opportunities and challenges in the development of experimental drug combinations for cancer. $J$. Natl. Cancer Inst. 103, 1222-1226

46. Fischbach, M. (2011) Combination therapies for combating antimicrobial resistance. Curr. Opin. Microbiol. 14, 519-523

47. Ryom, L. et al. (2018) Highlights of the 2017 European AIDS Clinical Society (EACS) Guidelines for the treatment of adult HIVpositive persons version 9.0. HIV Med. 19, 309-315

48. Geary, T. et al. (2012) World Association for the Advancement of Veterinary Parasitology (W.A.A.V.P.) Guideline: Anthelmintic combination products targeting nematode infections of ruminants and horses. Vet. Parasitol. 190, 306-316

49. Bartram, D. et al. (2012) The role of combination anthelmintic formulations in the sustainable control of sheep nematodes. Vet. Parasitol. 186, 151-158

50. Leathwick, D. et al. (2012) Managing anthelmintic resistance use of a combination anthelmintic and leaving some lambs untreated to slow the development of resistance to ivermectin. Vet. Parasitol. 187, 285-294

51. Leathwick, D. et al. (2015) Evidence for reversion towards anthelmintic susceptibility in Teladorsagia circumcincta in response to resistance management programmes. Int. J. Parasitol. Drugs Drug Resist. 5, 9-15

52. Dobson, R. et al. (2011) Minimising the development of anthelmintic resistance, and optimising the use of the novel anthemintic monepantel, for the sustainable control of nematode parasites in Australian sheep grazing systems. Aust. Vet. $J$ 89, 160-166

53. Canton, C. et al. (2017) Resistant nematodes in cattle: pharmaco-therapeutic assessment of the ivermectin- ricobendazole combination. Vet. Parasitol. 234, 40-48

54. Leathwick, D. (2012) Modelling the benefits of a new class of anthelmintic in combination. Vet. Parasitol. 186, 93-100

55. Leathwick, D. (2013) Managing anthelmintic resistance - parasite fitness, drug use strategy and the potential for reversion towards susceptibility. Vet. Parasitol. 198, 145-153

56. Leathwick, D. and Besier, R. (2014) The management of anthel mintic resistance in grazing ruminants in Australasia - strategies and experiences. Vet. Parasitol. 204, 44-54

57. Suarez, G. et al. (2014) Evaluation of pharmacological interactions after administration of a levamisole, albendazole and ivermectin triple combination in lambs. Vet. Parasitol. 201, 110-119

58. Leathwick, D. et al. (2016) The efficacy and plasma profiles of abamectin plus levamisole combination anthelmintics administered as oral and pour-on formulations to cattle. Vet. Parasitol. 227, 85-92

59. Keiser, J. et al. (2012) Effect of combinations of marketed human anthelmintic drugs against Trichuris murisin vitro and in vivo. Parasites Vectors 5, 292

60. Puttachary, S. et al. (2013) Derquantel and abamectin: effects and interactions on isolated tissues of Ascaris suum Mol. Biochem. Parasitol. 188, 79-86 from research in livestock animals be useful in optimising control and delay resistance development in soil-transmitted helminths in humans? 
61. Miller, D. and Craig, T. (1996) Use of anthelmintic combinations against multiple resistant Haemonchus contortus in Angora goats. Small Rumin. Res. 19, 281-283

62. Edmonds, M. et al. (2018) Concurrent treatment with a macrocyclic lactone and benzimidazole provides season long performance advantages in grazing cattle harboring macrocyclic lactone resistant nematodes. Vet. Parasitol. 252, 157-162

63. Anderson, N. et al. (1991) The efficacy of mixtures of albendazole sulphoxide and levamisole against sheep nematodes resistant to benzimidazole and levamisole. Aust. Vet. J. 68, 127-132

64. Entrocasso, C. et al. (2008) Clinical efficacy assessment of the albendazole-ivermectin combination in lambs parasitized with resistant nematodes. Vet. Parasitol. 155, 249-256

65. Le Jambre, L. et al. (2010) Efficacy of combination anthelmintics against multiple resistant strains of sheep nematodes. Anim. Prod. Sci. 50, 946-952

66. Ashraf, S. et al. (2015) Macrocyclic lactones and their relationship to the SNPS related to benzimidazole resistance. $\mathrm{Mol}$. Biochem. Parasitol. 201, 128-134

67. Trowbridge, A. (2014) Evolutionary ecology of chemically mediated plant-insect interactions. In Ecology and the Environment (Monson, R., ed.), pp. 143-176, Springer

68. Vattekkatte, A. et al. (2018) Enhanced structural diversity in terpenoid biosynthesis: enzymes, substrates and cofactors. Org. Biomol. Chem. 16, 348-362

69. Ribeiro, D. et al. (2013) Interação entre o óleo essencial de alecrim (Rosmarinus officinalis L.) e drogas antimicrobianas no controle de bactérias isoladas de alimentos. J. Biotechnol. Biodivers. 4, 1

70. Macedo, I. et al. (2015) Anthelmintic activity of Cymbopogon citratus against Haemonchus contortus. Rev. Bras. Parasitol. Vet. 24, 268-275

71. Katiki, L. et al. (2017) Synergistic interaction of ten essential oils against Haemonchus contortus in vitro. Vet. Parasitol. 243, $47-51$

72. Mesquita de Aquino, M. et al. (2013) Anthelmintic activity of Eucalyptus staigeriana encapsulated oil on sheep gastrointestinal nematodes. Parasitol. Res. 112, 3161-3165

73. Andre, W. et al. (2016) Comparative efficacy and toxic effects of carvacryl acetate and carvacrol on sheep gastrointestinal nematodes and mice. Vet. Parasitol. 218, 52-58

74. Peña-Espinoza, M. et al. (2016) Anthelmintic effects of forage (Cichorium intybus) against gastrointestinal nematode parasites in experimentally infected cattle. Parasitology 143, 1279-1293

75. Peña-Espinoza, M. et al. (2017) Anthelmintic effects of forage chicory (Cichorium intybus) against free-living and parasitic stages of Cooperia oncophora. Vet. Parasitol. 243, 204-207

76. Ahmad, A. et al. (2015) Synergistic interactions of eugenoltosylate and its congeners with fluconazole against Candida albicans. PLoS One 10, 1-19

77. Araújo, L. et al. (2016) Synergism of thymol, carvacrol and eugenol in larvae of the cattle tick, Rhipicephalus microplus, and brown dog tick, Rhipicephalus sanguineus. Med. Vet. Entomol. 30, 377-382

78. Miyazawa, M. et al. (2016) Chemical composition, aroma evaluation, and inhibitory activity towards acetylcholinesterase of essential oils from Gynura bicolor DC. J. Nat. Med. 70, 282-289

79. Trailović, S. et al. (2015) Interaction of carvacrol with the Ascaris suum nicotinic acetylcholine receptors and gamma-aminobutyric acid receptors, potential mechanism of antinematodal action. Parasitol. Res. 114, 3059-3068

80. Lei, J. et al. (2010) Nematicidal activity of two monoterpenoids and SER-2 tyramine receptor of Caenorhabditis elegans. Biochem. Pharmacol. 79, 1062-1071

81. Lynagh, T. et al. (2014) Comparative pharmacology of flatworm and roundworm glutamate-gated chloride channels: implications for potential anthelmintics. Int. J. Parasitol. Drugs Drug Resist. 4, 244-255
82. Eid, S. et al. (2013) Influence of combinations of digitonin with selected phenolics, terpenoids, and alkaloids on the expression and activity of P-glycoprotein in leukaemia and colon cancer cells. Phytomedicine 21, 47-61

83. Hoste, H. et al. (2016) Interactions between nutrition and infections with Haemonchus contortus and related gastrointestinal nematodes in small ruminants. Adv. Parasitol. 93, 239-351

84. Hoste, H. et al. (2012) Direct and indirect effects of bioactive tannin-rich tropical and temperate legumes against nematode infections. Vet. Parasitol. 186, 18-27

85. Hansen, T. et al. (2016) Proanthocyanidins inhibit Ascaris suum glutathione-S-transferase activity and increase susceptibility of larvae to levamisole in vitro. Parasitol. Int. 65, 336-339

86. Lopes, S. et al. (2016) Effect of tanniniferous food from Bauhinia pulchella on pasture contamination with gastrointestinal nematodes from goats. Parasites Vectors 9, 102

87. Spiegler, V. et al. (2017) Transcriptome analysis reveals molecular anthelmintic effects of procyanidins in C. elegans. PLoS One 12, e0184656

88. Jonker, A and Yu, P. (2016) The role of proanthocyanidins complex in structure and nutrition interaction in Alfalfa forage. Int. J. Mol. Sci. 17, E793

89. Testai, L. (2015) Flavonoids and mitochondrial pharmacology: a new paradigm for cardioprotection. Life Sci. 135, 68-76

90. Conseil, G. et al. (1998) Flavonoids: a class of modulators with bifunctional interactions at vicinal ATP- and steroid-binding sites on mouse P-glycoprotein. Proc. Natl. Acad. Sci. U. S. A. 95, 9831-9836

91. Dupuy, J. et al. (2003) Enhancement of moxidectin bioavailability in lamb by a natural flavonoid: quercetin. Vet. Parasitol. 112, 337-347

92. Heckler, R. et al. (2014) P-gp modulating drugs greatly potentiate the in vitro effect of ivermectin against resistant larvae of Haemonchus placei. Vet. Parasitol. 205, 638-645

93. Ferreira, L. et al. (2013) In vitro anthelmintic activity of aqueous leaf extract of Annona muricata L. (Annonaceae) against Haemonchus contortus from sheep. Exp. Parasitol. 134, 327-332

94. Gaudin, E. et al. (2016) Efficacy of sainfoin (Onobrychis vicilfolia) pellets against multi resistant Haemonchus contortus and interaction with oral ivermectin: implications for on-farm control. Vet. Parasitol. 227, 122-129

95. Klongsiriwet, C. et al. (2015) Synergistic inhibition of Haemonchus contortus exsheathment by flavonoid monomers and condensed tannins. Int. J. Parasitol. Drugs Drug Resist. 5, 127-134

96. Hoste, $\mathrm{H}$. and Torres-Acosta, J. (2011) Non chemical control of helminths in ruminants: adapting solutions for changing worms in a changing world. Vet. Parasitol. 180, 144-154

97. Canton, C. et al. (2018) Pharmaco-parasitological evaluation of the ricobendazole plus levamisole nematodicidal combination in cattle. J. Vet. Pharmacol. Ther. 41, 83-91

98. Ramos, F. et al. (2016) Anthelmintic resistance in gastrointestina nematodes of beef cattle in the state of Rio Grande do Sul, Brazil. Int. J. Parasitol. Drugs Drug Resist. 6, 93-101

99. Alvarez, L. et al. (2007) Drug transfer into target helminth parasites. Trends Parasitol. 23, 97-104

100. Mottier, L. et al. (2006) Drug transport mechanisms in helminth parasites: passive diffusion of benzimidazole anthelmintics. Exp. Parasitol. 113, 49-57

101. Lanusse, C. et al. (2015) Basic and clinical pharmacology contribution to extend anthelmintic molecules lifespan. Vet. Parasitol. 212, 35-46

102. Virkel, G. et al. (2003) Effect of amphiphilic surfactant agents on the gastrointestinal absorption of albendazole in cattle. Biopharm. Drug Dispos. 24, 95-103

103. Ceballos, L. et al. (2011) Comparative performances of flubendazole and albendazole in cystic echinococcosis: ex vivo activ ity, plasma/cyst disposition, and efficacy in infected mice. Antimicrob. Agents Chemother. 55, 5861-5867 
104. Ceballos, L. et al. (2015) Pharmacokinetic comparison of different flubendazole formulations in pigs: a further contribution to its development as a macrofilaricide molecule. Int. J. Parasitol. Drugs Drug Resist. 5, 178-184

105. García, J. et al. (2003) Bioavailability and efficacy characteristics of two different oral liquid formulations of albendazole. Int. J. Pharm. 250, 351-358

106. Rigter, I. et al. (2004) Relative bioavailability of three newly developed albendazole formulations: a randomized crossover study with healthy volunteers. Antimicrob. Agents Chemother. 48, 1051-1054

107. Castro, S. et al. (2013) Enhanced dissolution and systemic availability of albendazole formulated as solid dispersions. Pharm. Dev. Technol. 18, 434-442

108. Pensel, P. et al. (2015) Cystic echinococcosis therapy: albendazole-loaded lipid nanocapsules enhance the oral bioavailability and efficacy in experimentally infected mice. Acta Trop. 152, 185-194

109. Sánchez, S. et al. (2000) Enhanced plasma and target tissue availabilities of albendazole and albendazole sulphoxide in fasted calves: evaluation of different fasting intervals. J. Vet. Pharmacol. Ther. 23, 193-201

110. Ali, D. and Hennessy, D. (1995) The effect of reduced feed intake on the efficacy of oxfendazole against benzimidazole resistant Haemonchus contortus and Trichostrongylus colubriformis in sheep. Int. J. Parasitol. 25, 71-74

111. Hennessy, D. et al. (1995) The effect of a short-term reduction in feed on the pharmacokinetics and efficacy of albendazole in sheep. Aust. Vet. J. 72, 29-30

112. Lloberas, M. et al. (2012) Measurement of ivermectin concentrations in target worms and host gastrointestinal tissues: influence of the route of administration on the activity against resistant Haemonchus contortus in lambs. Exp. Parasitol. 131, 304-309

113. Leathwick, D. and Miller, C. (2013) Efficacy of oral, injectable and pour-on formulations of moxidectin against gastrointestinal nematodes in cattle in New Zealand. Vet. Parasitol. 191, 293-300

114. Alvarez, L. et al. (2012) Dose-dependent systemic exposure of albendazole metabolites in lambs. J. Vet. Pharmacol. Ther. 35, 365-372
115. Alvarez, L. et al. (2015) Integrated assessment of ivermectin pharmacokinetics, efficacy against resistant Haemonchus contortus and P-glycoprotein expression in lambs treated at three different dosage levels. Vet. Parasitol. 210, 53-63

116. Lloberas, M. et al. (2015) Comparative pharmacokinetic and pharmacodynamic response of single and double intrarumina doses of ivermectin and moxidectin in nematode-infected lambs. N. Z. Vet. J. 63, 227-234

117. Barrère, V. et al. (2012) Relationship between increased albendazole systemic exposure and changes in single nucleotide polymorphisms on the $\beta$-tubulin isotype 1 encoding gene in Haemonchus contortus. Vet. Parasitol. 186, 344-349

118. Saumell, C. et al. (2017) The route of administration drastically affects ivermectin activity against small strongyles in horses. Vet. Parasitol. 236, 62-67

119. Ballent, M. et al. (2006) Modulation of the P-glycoprotein-mediated intestinal secretion of ivermectin: in vitro and in vivo assessments. Drug Metab. Dispos. 34, 457-463

120. Dupuy, J. et al. (2010) Interaction of anthelmintic drugs with $P$ glycoprotein in recombinant LLC-PK1-mdr1a cells. Chem. Bio. Interact. 186, 280-286

121. Ballent, M. et al. (2014) Intestinal drug transport: ex vivo evaluation of the interactions between $\mathrm{ABC}$ transporters and anthelmintic molecules. J. Vet. Pharmacol. Ther. 37, 332-337

122. David, M. et al. (2018) Structural model, functional modulation by ivermectin and tissue localization of Haemonchus contortus P-glycoprotein-13. Int. J. Parasitol. Drugs Drug Resist. 1. 145-157

123. Bartram, D. (2013) Multiple-active anthelmintic formulations: friend or foe in sustainable parasite control? Small Rumin. Res. 110, 96-99

124. Van Wyk, J. (2001) Refugia - overlooked as perhaps the most potent factor concerning the development of anthelmintic resistance. Onderstepoort J. Vet. Res. 68, 55-67

125. Leathwick, D. et al. (2009) Managing anthelmintic resistance: is it feasible in New Zealand to delay the emergence of resistance to a new anthelmintic class? N. Z. Vet. J. 57, 181-192 